This is an electronic reprint of the original article. This reprint may differ from the original in pagination and typographic detail.

Author(s): Skalyga, V.; Izotov, I.; Golubev, S.; Vodopyanov, A.; Tarvainen, Olli

Title: $\quad$ First experiments with gasdynamic ion source in CW mode

Year: $\quad 2016$

Version:

Please cite the original version:

Skalyga, V., Izotov, I., Golubev, S., Vodopyanov, A., \& Tarvainen, O. (2016). First experiments with gasdynamic ion source in CW mode. Review of Scientific Instruments, 87(2), Article 02A715. https://doi.org/10.1063/1.4934208

All material supplied via JYX is protected by copyright and other intellectual property rights, and duplication or sale of all or part of any of the repository collections is not permitted, except that material may be duplicated by you for your research use or educational purposes in electronic or print form. You must obtain permission for any other use. Electronic or print copies may not be offered, whether for sale or otherwise to anyone who is not an authorised user. 


\section{AIP $\mid \begin{aligned} & \text { Review of } \\ & \text { Scientific Instruments }\end{aligned}$}

\section{First experiments with gasdynamic ion source in CW mode}

V. Skalyga, I. Izotov, S. Golubev, A. Vodopyanov, and O. Tarvainen

Citation: Review of Scientific Instruments 87, 02 A715 (2016); doi: 10.1063/1.4934208

View online: http://dx.doi.org/10.1063/1.4934208

View Table of Contents: http://scitation.aip.org/content/aip/journal/rsi/87/2?ver=pdfcov

Published by the AIP Publishing

\section{Articles you may be interested in}

Glow plasma trigger for electron cyclotron resonance ion sourcesa)

Rev. Sci. Instrum. 81, 02A305 (2010); 10.1063/1.3258025

Ion beam formation in a gas-dynamic electron cyclotron resonance ion source

Rev. Sci. Instrum. 77, 03 A341 (2006); 10.1063/1.2173966

Electron cyclotron resonance negative ion source

Rev. Sci. Instrum. 71, 935 (2000); 10.1063/1.1150350

Tornado-type closed magnetic trap for an electron cyclotron resonance ion source

Rev. Sci. Instrum. 71, 921 (2000); 10.1063/1.1150346

Effect of a biased probe on the afterglow operation of an ECR4 ion source

Rev. Sci. Instrum. 71, 863 (2000); 10.1063/1.1150314

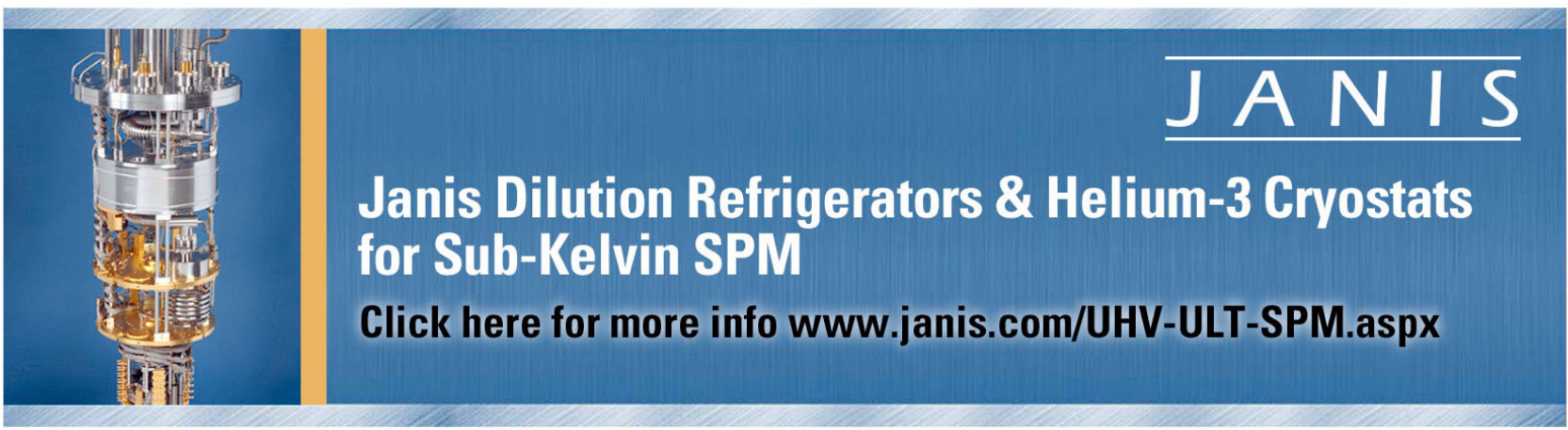




\title{
First experiments with gasdynamic ion source in CW mode
}

\author{
V. Skalyga, ${ }^{1,2, a)}$ I. Izotov, ${ }^{1}$ S. Golubev,${ }^{1}$ A. Vodopyanov, ${ }^{1,2}$ and O. Tarvainen ${ }^{3}$ \\ ${ }^{1}$ Institute of Applied Physics, Russian Academy of Sciences (IAP RAS), 46 Ul'yanova St., \\ Nizhny Novgorod 603950, Russia \\ ${ }^{2}$ Lobachevsky State University of Nizhny Novgorod (UNN), 23 Gagarina St., Nizhny Novgorod 603950, Russia \\ ${ }^{3}$ Department of Physics, University of Jyvaskyla, P.O. Box 35 (YFL), 40500 Jyvaskyla, Finland
}

(Presented 24 August 2015; received 5 September 2015; accepted 7 October 2015; published online 26 October 2015)

\begin{abstract}
A new type of ECR ion source-a gasdynamic ECR ion source-has been recently developed at the Institute of Applied Physics. The main advantages of such device are extremely high ion beam current with a current density up to $600-700 \mathrm{emA} / \mathrm{cm}^{2}$ in combination with low emittance, i.e., normalized RMS emittance below $0.1 \pi \mathrm{mm}$ mrad. Previous investigations were carried out in pulsed operation with 37.5 or $75 \mathrm{GHz}$ gyrotron radiation with power up to $100 \mathrm{~kW}$ at SMIS 37 experimental facility. The present work demonstrates the first experience of operating the gasdynamic ECR ion source in CW mode. A test bench of SMIS 24 facility has been developed at IAP RAS. $24 \mathrm{GHz}$ radiation of $\mathrm{CW}$ gyrotron was used for plasma heating in a magnetic trap with simple mirror configuration. Initial studies of plasma parameters were performed. Ion beams with pulsed and CW high voltage were successfully extracted from the $\mathrm{CW}$ discharge. Obtained experimental results demonstrate that all advantages of the gasdynamic source can be realized also in CW operation. $\odot 2015$ AIP Publishing LLC. [http://dx.doi.org/10.1063/1.4934208]
\end{abstract}

\section{INTRODUCTION}

Investigations in the field of gasdynamic ECR plasma confinement in recent years resulted in development of pulsed high current ion sources capable to deliver ion beams with 100-500 mA current and normalized RMS emittance below $0.1 \pi \mathrm{mm}$ mrad. ${ }^{1-6}$ Such results became possible, thanks to key features of quasi-gasdynamic plasma confinement in the case of heating with mm-waveband gyrotron radiation, namely, high plasma density and low plasma lifetime., ${ }^{7,8}$ While the pulsed operation of gasdynamic ion sources was studied in details ${ }^{1-8}$ such devices have not been tested in CW mode before. In recent years, a new SMIS 24 experimental facility was installed at the Institute of Applied Physics of Russian Academy of Sciences (Nizhniy Novgorod, Russia). At SMIS 24 , the plasma is heated by $24 \mathrm{GHz}$ radiation of $\mathrm{CW}$ gyrotron and confined in a simple mirror trap similarly to SMIS 37 facility which was used for pulsed operation experiments. In this paper, the first results on CW ECR discharge ignition, study of plasma parameters, and ion beam extraction are presented.

\section{SMIS 24 EXPERIMENTAL FACILITY}

The photograph and scheme of SMIS 24 is shown in Fig. 1. The microwave radiation is produced by $\mathrm{CW} 24 \mathrm{GHz}$ $5 \mathrm{~kW}$ gyrotron (manufactured by $\mathrm{GYCOM}^{9}$ ). Radiation goes through microwave transmission line to a water-cooled DC-

\footnotetext{
Note: Contributed paper, published as part of the Proceedings of the 16th International Conference on Ion Sources, New York, New York, USA, August 2015.

a) Author to whom correspondence should be addressed. Electronic mail: skalyga@ipfran.ru
}

break which is designed up to $100 \mathrm{kV}$. Following the DCbreak, the radiation passes through a specially developed microwave coupling system optimized to maximize the electric field distribution on trap axis and minimize microwave reflection.

Plasma is created in the plasma chamber with $380 \mathrm{~mm}$ length and $38 \mathrm{~mm}$ diameter. The magnetic field is produced by a pair of water-cooled Bitter solenoids. The maximum magnetic field on trap axis reaches the value of $1.1 \mathrm{~T}$. The ratio between magnetic field at the magnetic mirror and the trap center is 5 and the distance between magnetic mirrors (trap length) is $180 \mathrm{~mm}$. The magnetic field distribution inside the plasma chamber is shown in Figure 2.

A two-electrode extraction system was used in the beam extraction experiments. In the first experiments, the plasma electrode and puller had $4 \mathrm{~mm}$ and $10 \mathrm{~mm}$ apertures, respectively. The available extraction voltage was in the range of 20-60 kV. Due to low power of the power supply, the extraction system was placed far behind the magnetic mirror to reduce the ion current density so that the total extracted current could meet the power supply maximum output. The plasma electrode (extractor) position together with the magnetic field distribution on axis and calculated expected ion current density is shown in Figure 3. The calculations are made by assuming $10^{13} \mathrm{~cm}^{-3}$ plasma density and electron average energy on the order of $100 \mathrm{eV}$. According to the estimation, we expected approximately $5.6 \mathrm{~mA}$ of total extracted ion current.

A Langmuir probe and a Faraday cup were used as diagnostic tools. The probe was used for the measurement of plasma flux parameters (electron temperature and spatial distribution). The Faraday cup was used to measure the total beam current. Argon was used in the experiments as a feeding gas in the pressure range of $10^{-6}-10^{-4}$ Torr. 

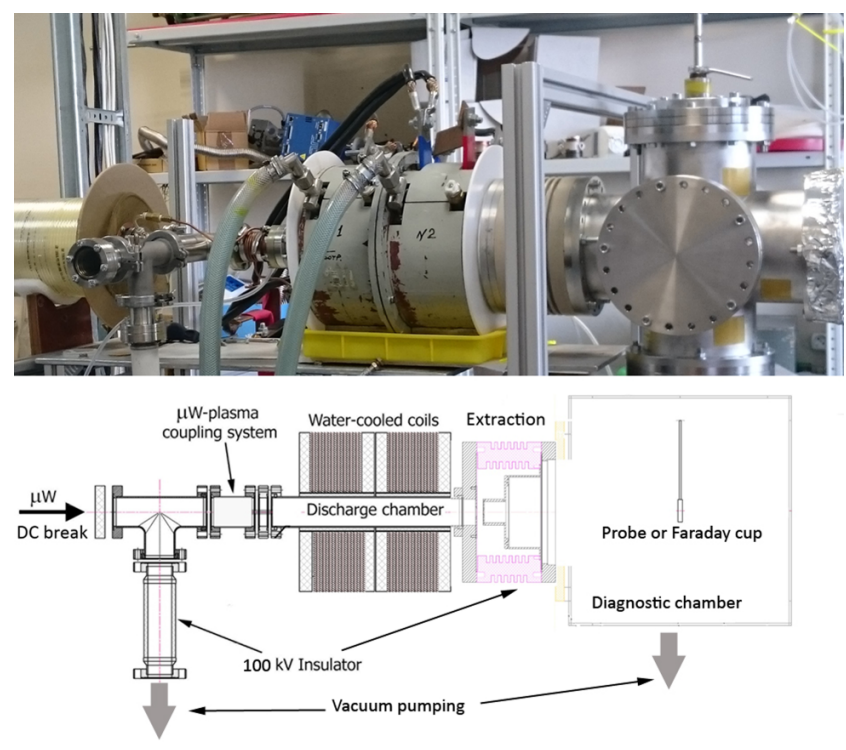

FIG. 1. SMIS 24 experimental facility. Gyrotron is on the left side (not shown).

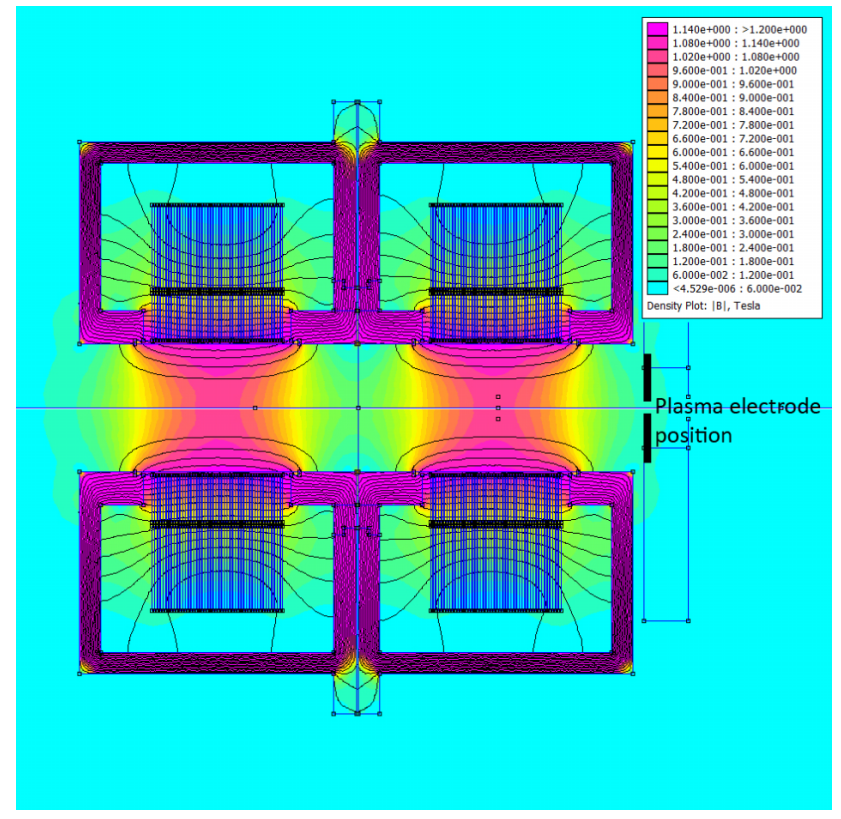

FIG. 2. Magnetic field structure of SMIS 24. Plasma electrode of the extraction system is schematically shown.

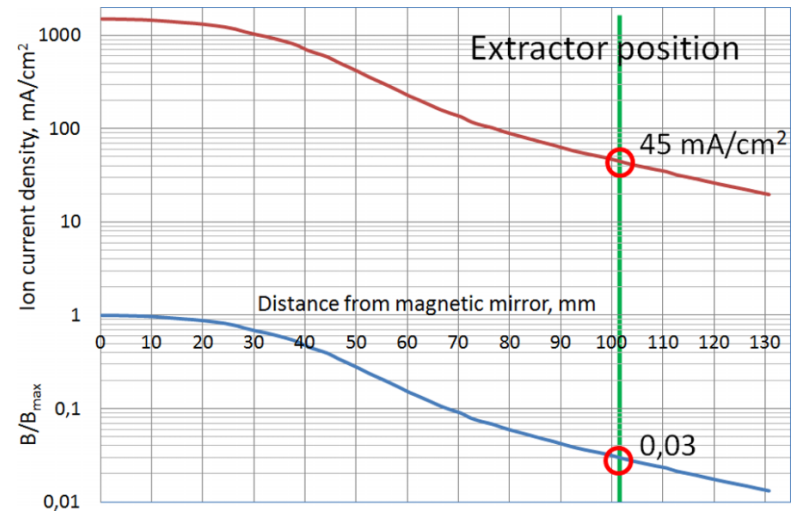

FIG. 3. Magnetic field distribution behind the magnetic mirror (blue). Calculated ion current density (red). Plasma electrode position (green).

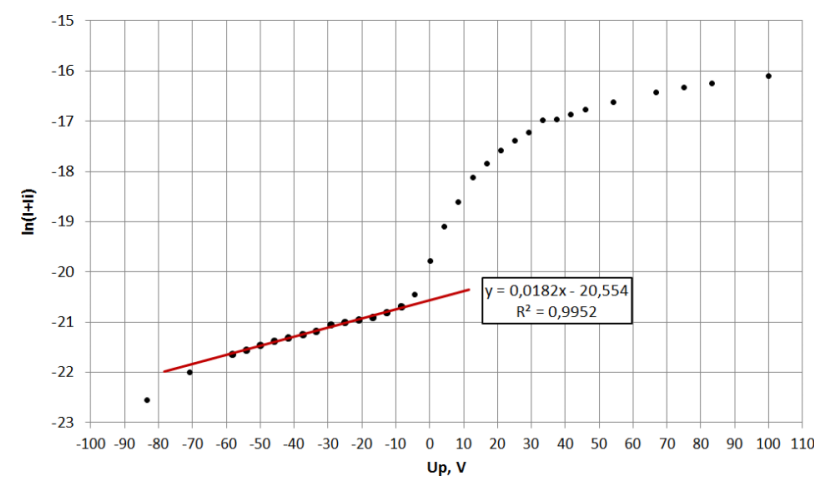

FIG. 4. Probe $\mathrm{I}-\mathrm{V}$ curve. Microwave power $=200$ W. Argon pressure $=6 \times 10^{-6}$ Torr.

\section{FIRST EXPERIMENTAL RESULTS}

As the first experimental step, Langmuir probe I-V curves were collected from the plasma flux escaping the trap in order to determine the electron temperature and spatial distribution of the flux density. An example of typical I-V curve is shown in Figure 4 in the case of $200 \mathrm{~W}$ microwave power and $6 \times 10^{-6}$ Torr neutral gas pressure. The measured electron temperature is $55 \mathrm{eV}$.

By moving the probe along the axis and measuring the ion saturation current, we measured the plasma flux density distribution, which is shown in Figure 5 together with the magnetic field distribution. It could be concluded from the figure that the plasma flux density approximately follows the magnetic field strength. This means that the plasma flux density at the magnetic mirror of the trap could be obtained by scaling the magnetic field. The corresponding maximum plasma flux density in our experiments reached $1 \mathrm{eA} / \mathrm{cm}^{2}$ at the magnetic mirror. This value fits our initial calculations on probable plasma parameters. Measured plasma flux density in the case of $55 \mathrm{eV}$ electron temperature under quasigasdynamic confinement corresponds to $1 \times 10^{13} \mathrm{~cm}^{-3}$ plasma density inside the trap.

The first ion beam was extracted with the configuration described above. All results shown in this paper were collected with $25 \mathrm{kV}$ extraction voltage. The total ion current dependence on neutral gas pressure is shown in Figure 6 for two microwave power levels. The flat part of the dependence probably corresponds to discharge conditions

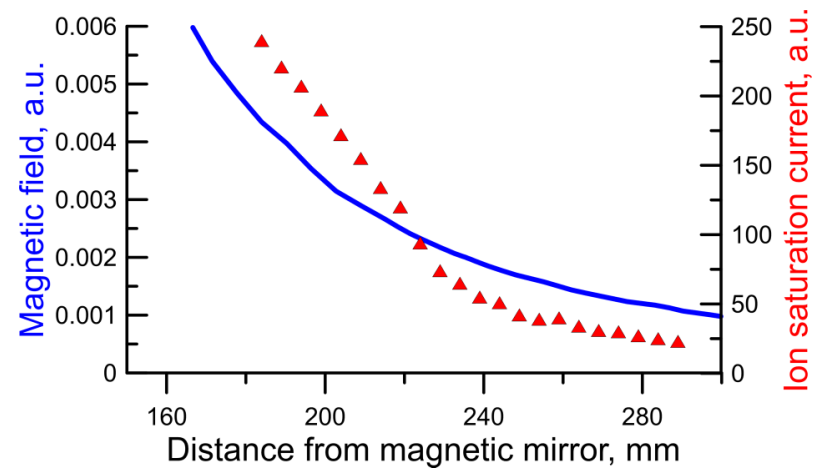

FIG. 5. Ion saturation current at different probe positions behind the magnetic mirror (red dots) and magnetic field distribution (blue line). 


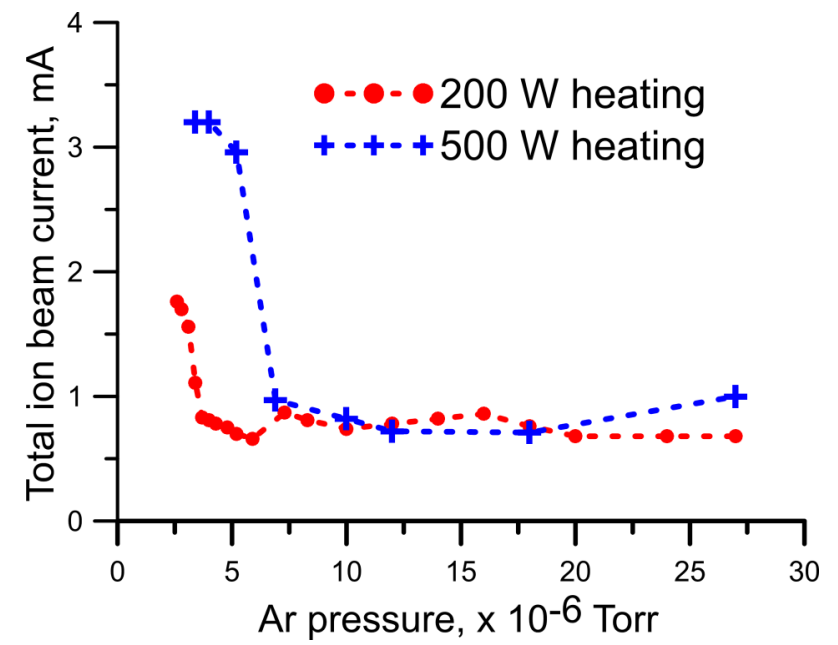

FIG. 6. Extracted ion current dependence on argon pressure for different microwave power levels.

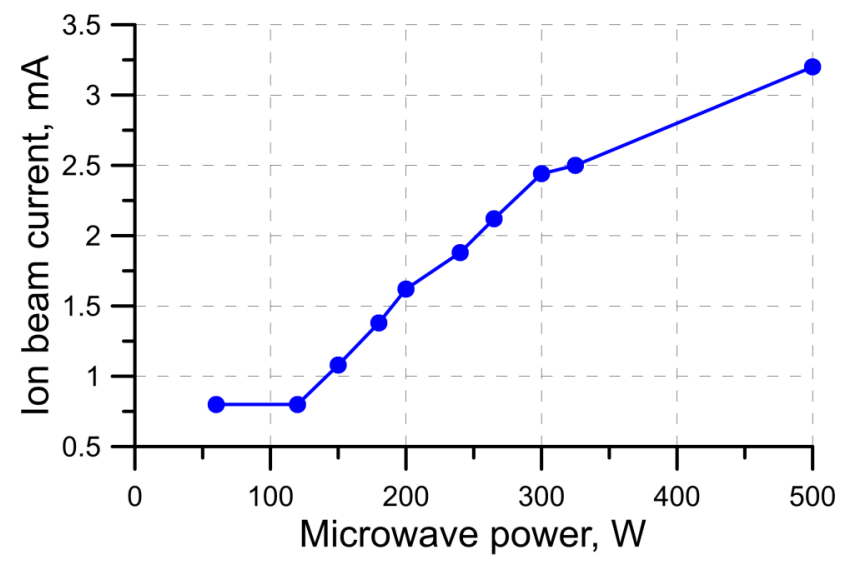

FIG. 7. Extracted ion current dependence on microwave power. Argon pressure $=6 \times 10^{-6}$ Torr.

with too high pressure for effective ECR heating with the given microwave power.

In this case, one could expect a plasma of cut-off density with electron temperature close to $10 \mathrm{eV}$ without observable pressure dependence. More effective plasma heating was obtained at lower pressure, which led to electron temperature growth and reduction of quasi-gasdynamic plasma lifetime, thus increasing the total current.
The same growing dependence of the extracted ion current was observed with the microwave power increase (see Figure 7).

The maximum beam current reached in the experiments was $3.2 \mathrm{emA}$ through $4 \mathrm{~mm}$ hole. It is of note that the total current could be significantly increased by shifting the extraction system closer to the magnetic mirror, up to the values demonstrated in pulsed operation mode at SMIS 37.

\section{CONCLUSION}

The first experimental study of CW ECR discharge with quasi-gasdynamic confinement sustained by $24 \mathrm{GHz}$ gyrotron radiation demonstrated that results similar to those obtained in pulsed mode at SMIS 37 could be reached. Stable operation with $1 \mathrm{eA} / \mathrm{cm}^{2}$ (estimated) of plasma flux density was observed in the experiments. This makes a formation of $\mathrm{CW}$ high current beams possible in close future in the frame of upcoming experiments. One of the most important steps will be an increase of the microwave power which becomes possible after an improvement of the plasma chamber cooling.

\section{ACKNOWLEDGMENTS}

The work was supported by RFBR under Grant No. 1308-00845 and the grant of the President of Russian Federation for young scientists under No. \#MK-6565.2014.2. The work of Ivan Izotov was supported by the fellowship of the President of Russian Federation for young scientists under No. \#SP7279.2013.2 and was also supported by the Academy of Finland under the Finnish Centre of Excellence Programme 2012-2017 (Nuclear and Accelerator Based Physics Research at JYFL) and researcher mobility under Grant Nos. 267174 and 267227.

${ }^{1}$ S. V. Golubev et al., Rev. Sci. Instrum. 75(5), 1675 (2004).

${ }^{2}$ S. V. Golubev et al., Trans. Fusion Sci. Technol. 47(1T), 345 (2005).

${ }^{3}$ A. Sidorov et al., Rev. Sci. Instrum. 77(3), 03A341 (2006).

${ }^{4}$ A. V. Vodopyanov et al., High Energy Phys. Nucl. Phys. 31(S1), 152 (2007).

${ }^{5}$ V. Skalyga et al., Rev. Sci. Instrum. 85(2), 02 A702 (2014).

${ }^{6}$ S. V. Golubev et al., Rev. Sci. Instrum 71(2), 669 (2000).

${ }^{7}$ V. Skalyga et al., Plasma Sources Sci. Technol. 15, 727 (2006).

${ }^{8}$ S. Golubev et al., Nucl. Instrum. Methods Phys. Res., Sect. B 256, 537 (2007).

${ }^{9}$ See www.gycom.ru for details about available gyrotrons. 